\title{
ARTICLE
}

\section{Geographical analysis of forest types based on a digital elevation model generated from synthetic aperture radar}

\author{
Nyamjargal Erdenebaatar* and Amarsaikhan Damdinsuren
}

Division of Remote Sensing and Spatial Modelling, Institute of Geography and Geoecology, Mongolian Academy of Sciences, Ulaanbaatar, Mongolia

Abstract: This research aims to examine forest type distribution, based on slope and aspect maps, generated from synthetic aperture radar (SAR) data. The study is conducted over an area about $1564.9 \mathrm{~km} 2$ located in Khutag-Undur soum of Bulgan aimag (province), northern Mongolia. Sentinel1 interferometric SAR images acquired on 5 and 17 October of 2020 are used to generate a digital elevation model (DEM). For a forest type classification, geocoded Sentinel-2 multispectral images acquired on 5 July and 27 September of 2019 are used. Initially, a DEM creation from the SAR data is performed and the slope and aspect maps are generated, following which geographical analysis is performed using slope, aspect and classified forest type maps. The result of the analysis shows that about half of the forested areas face the north-west, north and north-east directions. It also revealed that evergreen conifers are distributed on slopes of moderate degrees facing towards the south-east and south, whereas the deciduous conifers are mainly distributed on relatively steep slopes facing south-west, west and north-west.

Keywords: DEM; aspect map; slope map; forest type; Sentinel-1; Sentinel-2;

\section{INTRODUCTION}

A DEM is a physical representation of terrain and a very useful feature in different geographical analysis. It is used in many research areas including, modelling water flow for hydrology, terrain analysis in geomorphology and physical geography, landscape development, land use studies and forest analysis. The DEM is usually generated from optical stereo image pairs, interferometric
SAR images and LiDAR data [1]. In recent years, space SAR interferometry has been increasingly used for a DEM generation [2], because it is has all-day and all-weather working abilities, wide spatial coverage, fine spatial resolution, high measurement precision and makes redundant ground instrumentation [3].

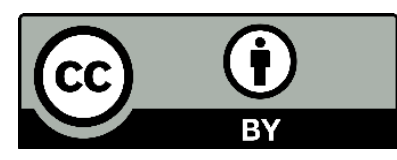

The Author(s). 2020 Open access This article is distributed under the terms of the Creative Commons Attribution 4.0 International License (https://creativecommons.org/licenses/by/4.0/), which permits unrestricted use, distribution, and reproduction in any medium, provided you give appropriate credit to the original author(s) and the source, provide a link to the Creative Commons license, and indicate if changes were made. 
In general, imaging radar systems use backscattering signals that contain amplitude and phase information [4]. The amplitude is the strength of the radar response and the phase is the fraction of one complete sine wave cycle (a single SAR wavelength). The phase of the SAR image is determined primarily by the distance between the satellite antenna and the ground targets. Interferometric SAR exploits the phase difference between two complex radar SAR observations of the same area, taken from slightly different sensor positions, and extracts distance information about the Earth's terrain [5]. By combining the phase of these two images after coregistration, an interferogram can be generated where phase is highly correlated to the terrain topography [6].

Over the past decade, several space-borne SAR missions have been carried out to acquire high resolution radar images. One of them is the Sentinel-1, the first of Copernicus Programme satellite constellation conducted by the European Space Agency (ESA) in 2014 [7]. The Sentinel-1 has an unbeatable mapping ability, because in interferometric wide swath (IW) mode, three sub-swaths imaged in the novel Terrain Observation by Progressive Scans (TOPS) SAR mode result in a total swath width of $250 \mathrm{~km}$. It is suitable for mapping and interferometric monitoring at a medium resolution [8] and can generate images with a medium spatial resolution once every 12 days.

At present, beside the Sentinel-1 radar data sets, different products of Sentinel-2A optical images are used for various thematic studies. Sentinel-2A is an Earth observation mission from the Copernicus Programme that systematically acquires multichannel data at a high spatial resolution over the Earth's surface. Since its commencement in 2015 [9], today scientists and researchers from different countries are conducting sophisticated geographical and spatial analyses, integrating both Sentinel-1 radar and Sentinel-2A optical data sets.
Mongolia has a long tradition in the application of microwave and optical data sets for different geographical studies, taking into account the forest, pasture vegetation and many other types of natural resources. The aim of this study is to conduct advanced geographical analysis and examine forest type distribution in a selected test sites of Mongolia on the basis of slope and aspect maps generated from interferometric SAR data. For the DEM generation, Sentinel-1 interferometric SAR images have been used, while for the forest mapping Sentinel-2A multispectral images were selected.

\section{Study area are data sources}

The study was conducted in KhutagUndur soum of Bulgan aimag, northern Mongolia. According to the Holdridge life zones' system of bioclimatic classification, Bulgan is situated in the boreal dry scrub biome (larch, birch and shrub), where larch accounts for 86.12 per cent of the trees and birch 13.88 per cent [4]. The Khutag-Undur soum's territory is $5100 \mathrm{~km} 2,40.2$ per cent of which is pasture, 38 per cent - forest, 7.7 percent are rivers and lakes, and 10.8 per cent are hayfields [10]. The terrain of study area is a combination of plain, hilly and rounded forested mountain with the highest pick of $1920 \mathrm{~m}$ above sea level. In addition, one of the national protected areas, the Uran Togoo - Tulga Uul Natural Monument is located in the south western part of the study area (Figure 1). Khutag-Undur has a humid continental climate with warm summers and severely cold winters. The mean annual temperature is $+1.5^{\circ} \mathrm{C}$ and mean precipitation is $242.9 \mathrm{~mm}$. The soil type is sandy with semi desert features in the southern part, while fertile land mainly appears in the north for crop cultivation. A forest report by the Ministry of Environment and Tourism described 5 species of trees and bushes in the Bulgan forests, such as larch (larix sibirica), pine (pinus silvestris), cedar (pinus cembra), birch (betula) and poplar (populus diversifolia) [11]. 


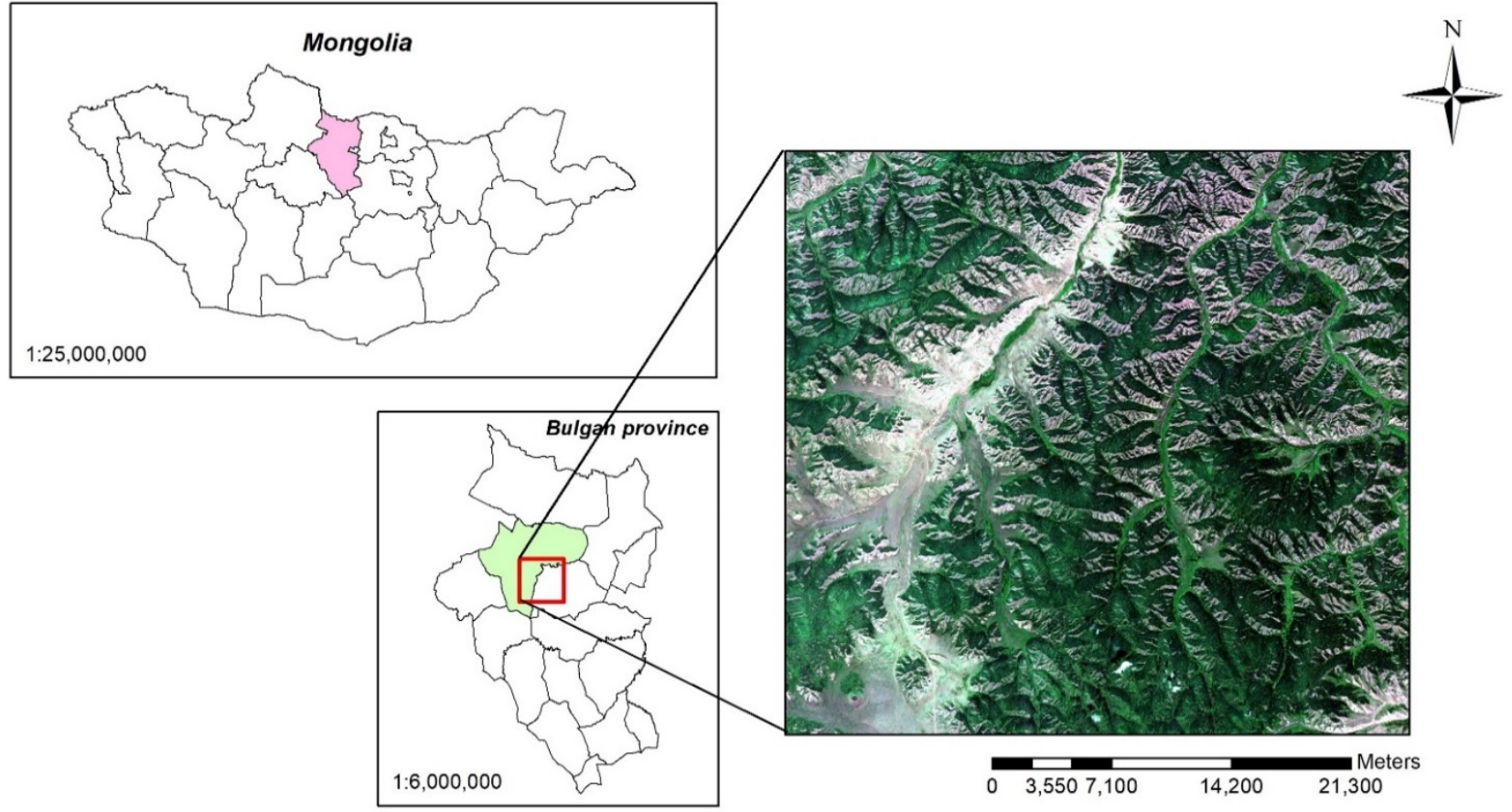

Figure 1. Location of the study site and RGB color composite of Sentinel-2 images

In the study, Sentinel-1 interferometric SAR images, downloaded from Copernicus Data Hub, were used to generate a DEM. The Sentinel-1 has a C-band SAR instrument operating at a frequency of $5.405 \mathrm{GHz}$, allowing the acquisition of imagery regardless of weather and illumination conditions. It acquires SAR data in single or dual polarization with a revisit time of 6 days and distributes two product types, namely, Ground Range Detected (GRD) and Single Look Complex (SLC) [12]. In this research, Sentinel-1B SLC images acquired on 5 and 17 October of 2020 were used (Figure 2).
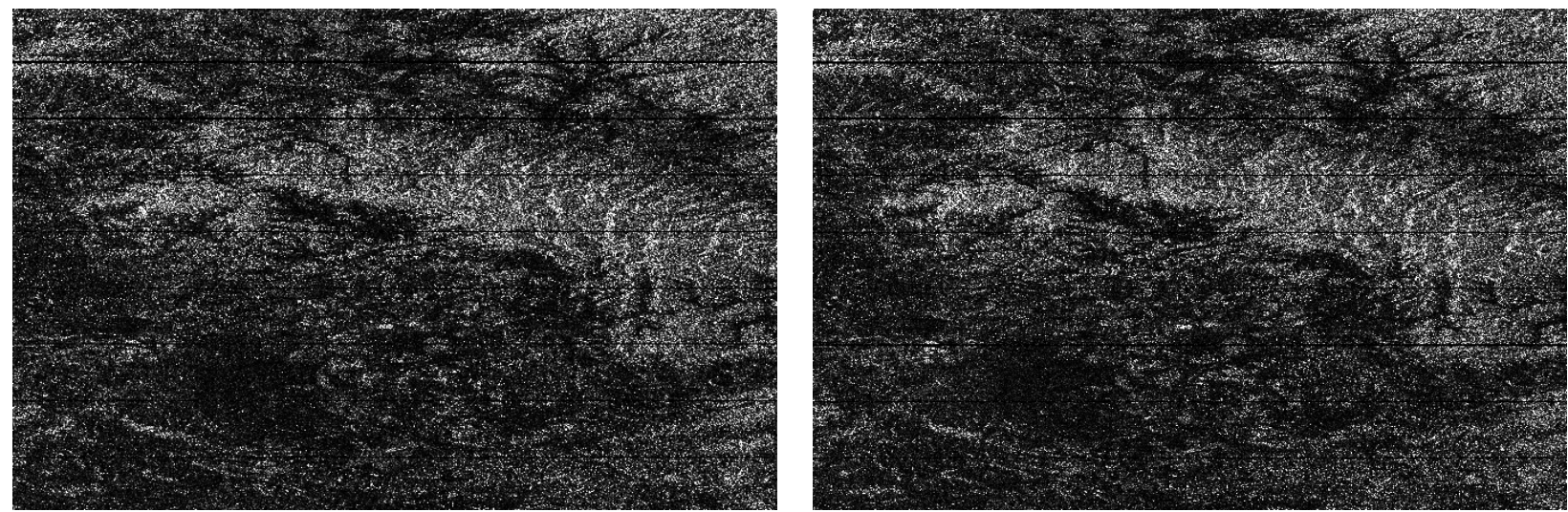

Figure 2. Sentinel-1 interferometric images:

a) (left image) acquired on 5 October 2020 and b) (right image) 17 October 2020

In the present study, optical satellite data consisted of geocoded Sentinel-2A multispectral images acquired on 5 July and 27 September 2019 (Figure 3) respectively. As the test area has mixed forest classes, such multitemporal data sets are important for differentiation among deciduous and evergreen conifer types. Sentinel-2A images have 12 spectral bands [13] and their characteristics are presented in Table 1. 


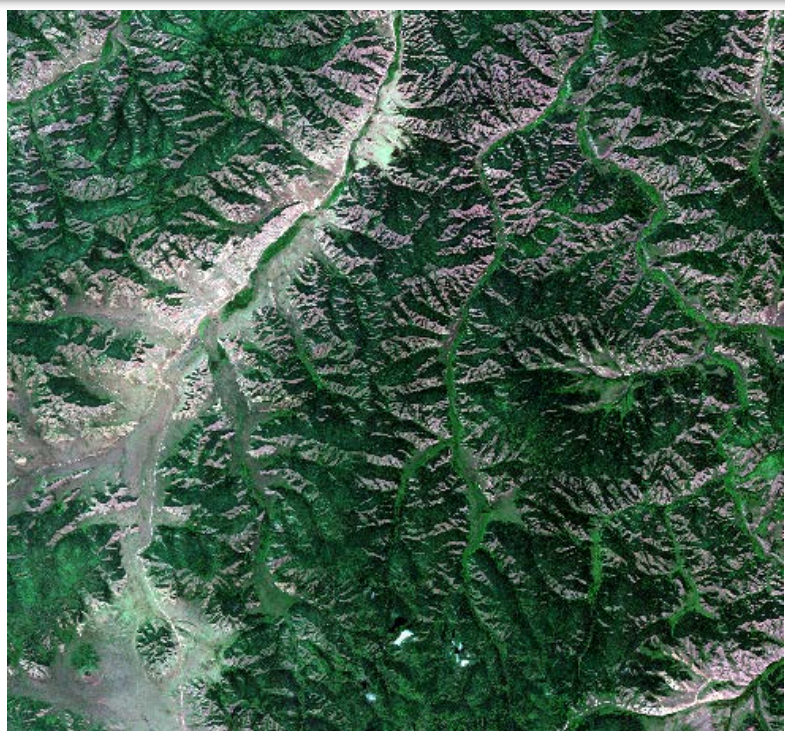

$3 a$.

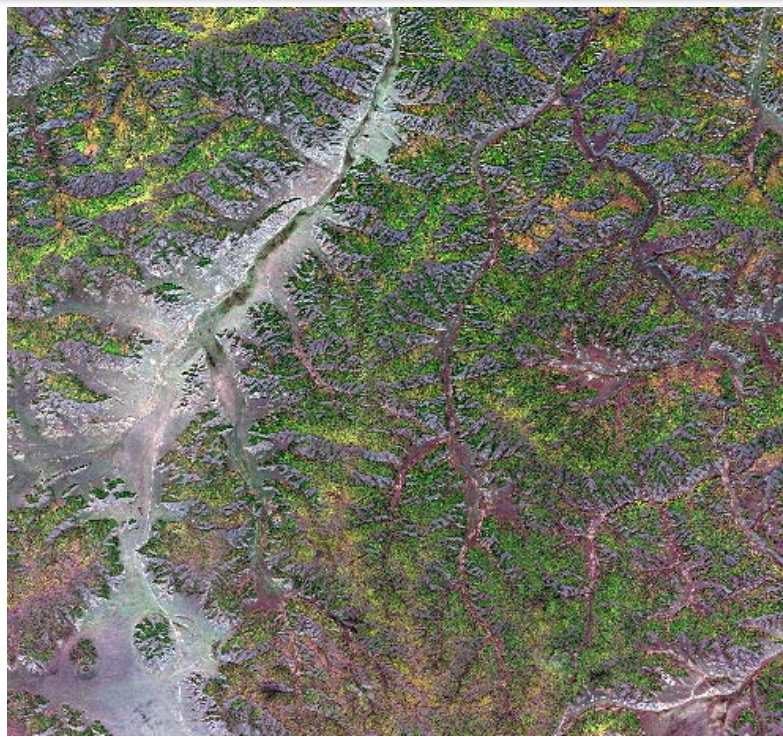

$3 b$.

Figure 3. Sentinel-2 images used for the study: a) 5 July 2019 and b) 27 September 2019

Table 1. Characteristics of spectral bands of Sentinel-2A.

\begin{tabular}{|c|c|c|c|c|c|}
\hline Band & $\begin{array}{c}\text { Wavelength } \\
(\mu \mathrm{m})\end{array}$ & $\begin{array}{c}\text { Spatial } \\
\text { resolution }(\mathrm{m})\end{array}$ & Band & $\begin{array}{c}\text { Wavelength } \\
(\mu \mathrm{m})\end{array}$ & $\begin{array}{c}\text { Spatial } \\
\text { resolution }(\mathrm{m})\end{array}$ \\
\hline Band 1 & 0.443 & 60 & Band 8 & 0.842 & 10 \\
\hline Band 2 & 0.490 & 10 & Band 8A & 0.865 & 20 \\
\hline Band 3 & 0.560 & 10 & Band 9 & 0.945 & 60 \\
\hline Band 4 & 0.665 & 10 & Band 10 & 1.375 & 60 \\
\hline Band 5 & 0.705 & 20 & Band 11 & 1.610 & 20 \\
\hline Band 6 & 0.740 & 20 & Band 12 & 2.190 & 20 \\
\hline Band 7 & 0.783 & 20 & & & \\
\hline
\end{tabular}

\section{MATERIALS AND METHODS}

Within the framework of the study, the research methodology consists of the following parts:

- DEM creation from the SAR data is performed;

- Slope and aspect maps are generated;

- Forest type mapping is conducted using optical images; and,
- Geographical analysis is performed combining slope, aspect and forest type maps.

A general scheme of the methodology can be illustrated as shown in Figure 4. For analysis, we used such software products as Sentinel Application Platform (SNAP), QGIS and eCognition Developer. 


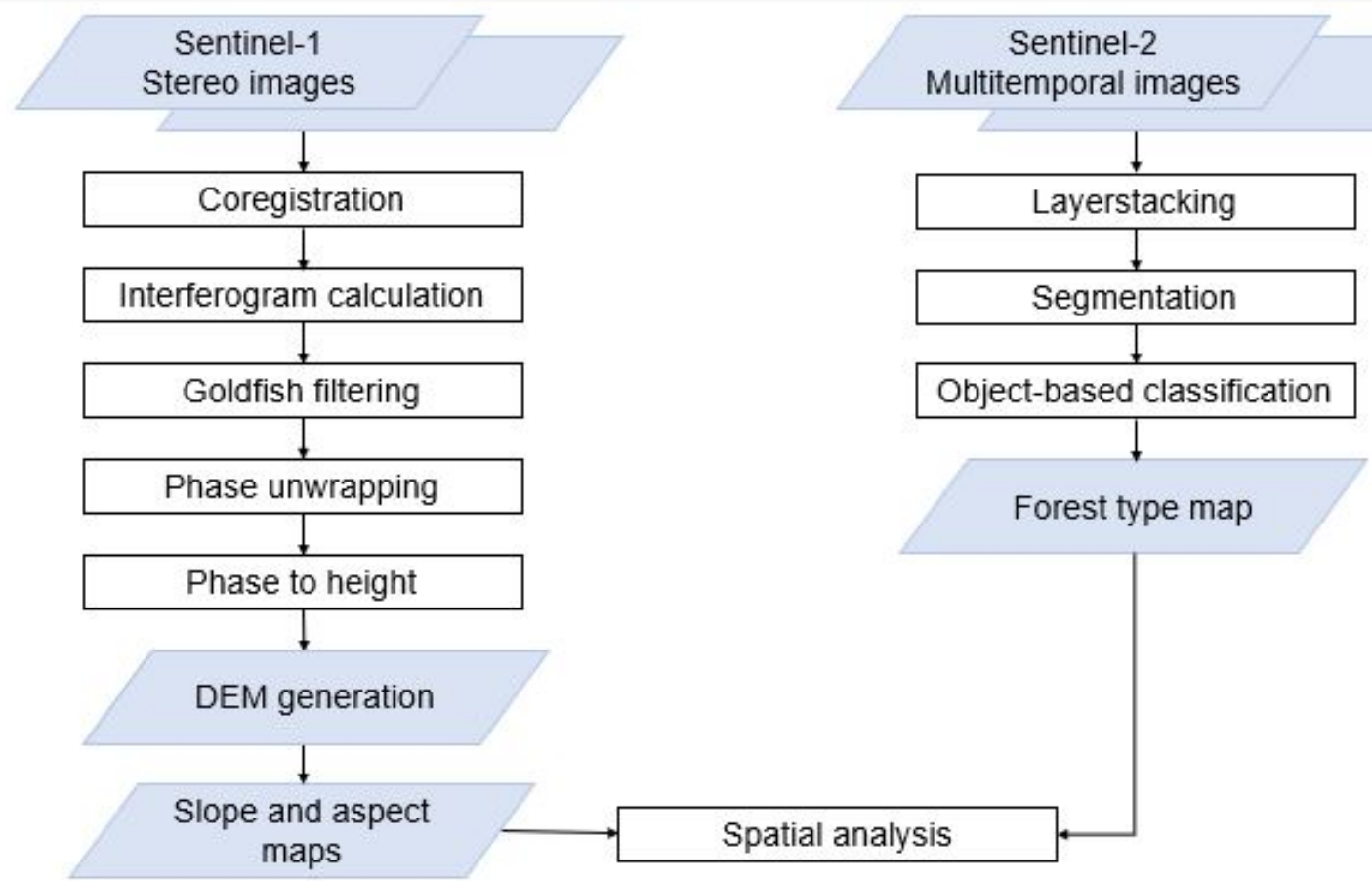

Figure 4. Data processing methodology

\section{DEM generation from the SAR data}

It is well known that a high accuracy DEM can be derived from SAR data sets by interferometric processing. The procedure to generate a DEM includes the below stages and is performed by SNAP software developed by the ESA.

1. For interferometric processing, two or more images must be coregistered into a stack. One image is selected as the master and the other images are the slaves. The pixels in slave images will be moved to align with the master image to a sub-pixel accuracy [14].

2. The next important step is to create an interferogram. The interferogram is formed by cross multiplying the master image with the complex conjugate of the slave. The amplitude of both images multiplied, while the phase presents the phase difference between two images. The interferogram is displayed in a rainbow color scale ranging from $-\pi$ to $+\pi$ and contains variations from topography, atmosphere and potential surface deformation (considered zero). The patterns, also called "fringes" represent a full $2 \pi$ cycle and appear in an interferogram as cycles of arbitrary colors, with each cycle representing half the sensor's wavelength [15].

3. In many cases, the created interferogram contains bursts. Due to various reasons such as natural condition, hard topography, error in co-registration processing and other reasons, interferogram image could be noisy. So, Goldstein filter is used for decreasing noise [16]. It is an adaptive filter that works in the space of frequencies maintaining the predominant frequencies of the interferometric phase and removing the noise.

4. Phase unwrapping solves this ambiguity by integrating phase differences between neighboring pixels. After deleting any integer number of altitudes of ambiguity (equivalent to an integer number of $2 \pi$ phase cycles), the phase variation between two points on the flattened interferogram provides a measurement of the actual altitude variation. Accordingly, unwrapped results should be interpreted as a relative height/displacement between pixels of two images [17].

5. The topographic phase is converted to height information with respect to the reference (height in slant range).

As a result of the interferometric SAR technique, a DEM with a $12 \mathrm{~m} \times 12 \mathrm{~m}$ pixel resolution has been generated from Sentinel-1 satellite data for the study area. The highest and lowest altitudes were $1962.268 \mathrm{~m}$ and 939.009 $\mathrm{m}$, respectively (Figure 5). 


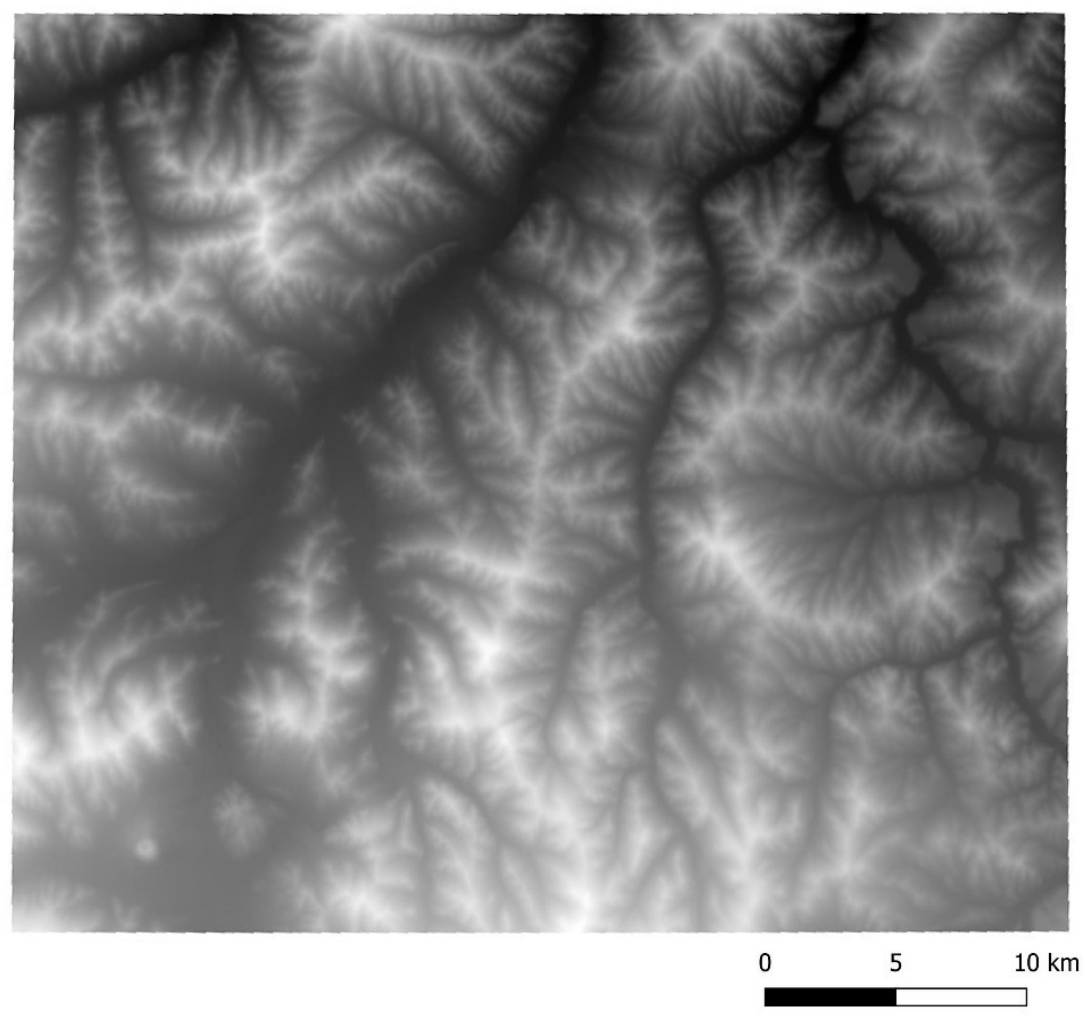

Figure 5. Generated DEM from Sentinel-1 images

\section{Creation of slope and aspect maps}

Slope is the steepness or the degree of incline of a surface. It can be expressed either in degrees or as a percentage. Aspect is the orientation of slope, measured clockwise in degrees from 0 to 360 , where 0 is north-facing, 90 is east-facing, 180 is south-facing and 270 is west-facing [18].

To convert the elevation data to slope value, a corresponding slope raster was computed from the DEM using a method of eight grid points with unequal weights. This is the standard method applied for a slope calculation in GDAL. Scale factors were applied to compensate for the fact that the horizontal positions of pixels in the DEM were presented in degrees, while the elevation was in meters.

To avoid projecting the global DEM onto a flat surface, as one would do with smaller study areas, different scale factors were used for every change in latitude. The following formula was used for the scale factors:

$$
\text { Scale factor }=111320 * \cos \frac{\text { latitude } * \pi}{180}
$$

where 111320 is a constant representing the number of meters in one-degree longitude at the equator. The scale factor is changed gradually according to equation 1 moving towards the poles, because one degree equals fewer and fewer meters in the east-west direction when moving away from the equator [19].

Figures 6 and 7 illustrate the generated from the DEM slope and aspect maps. 

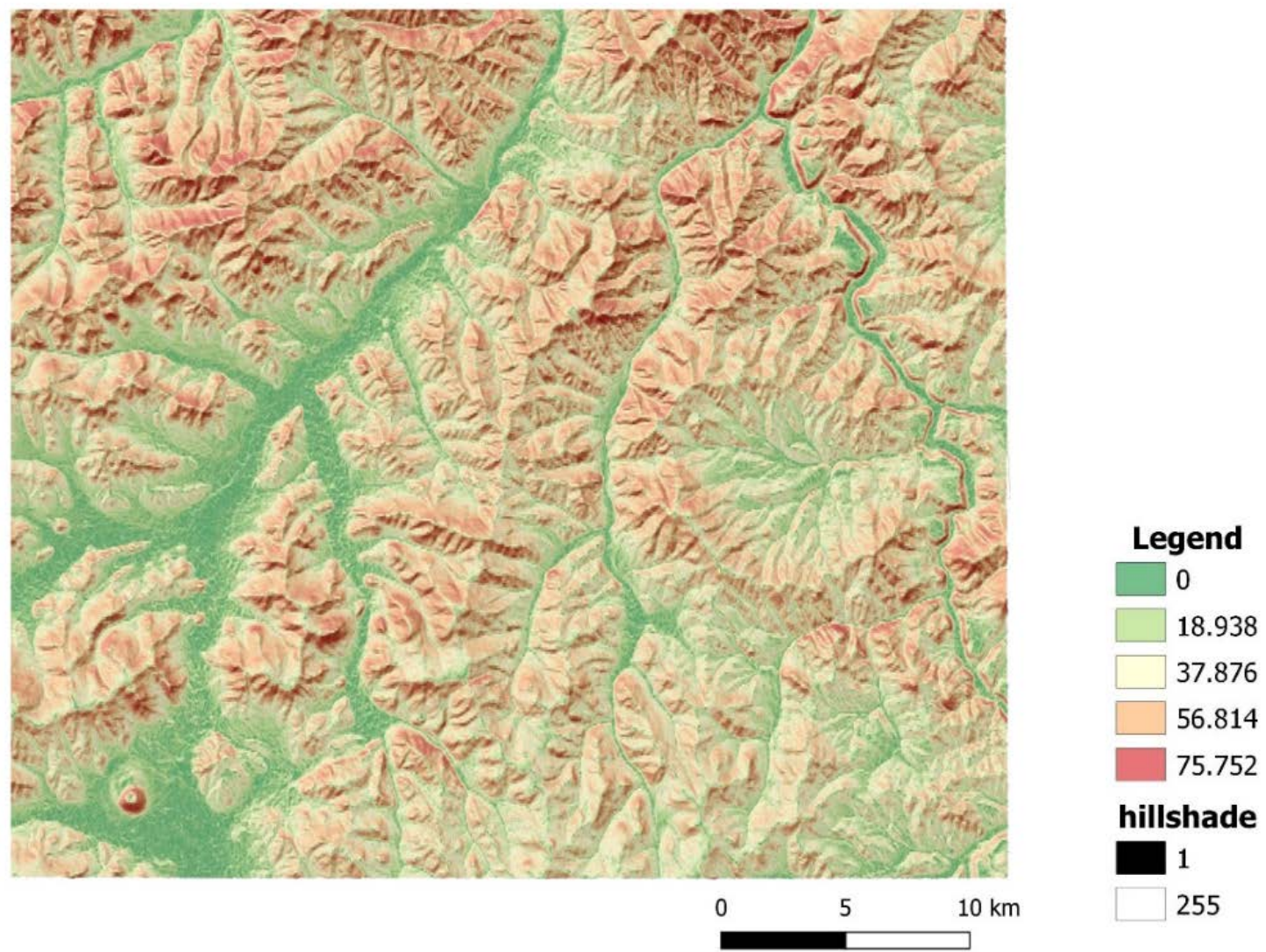

Figure 6. Calculated slope map from DEM
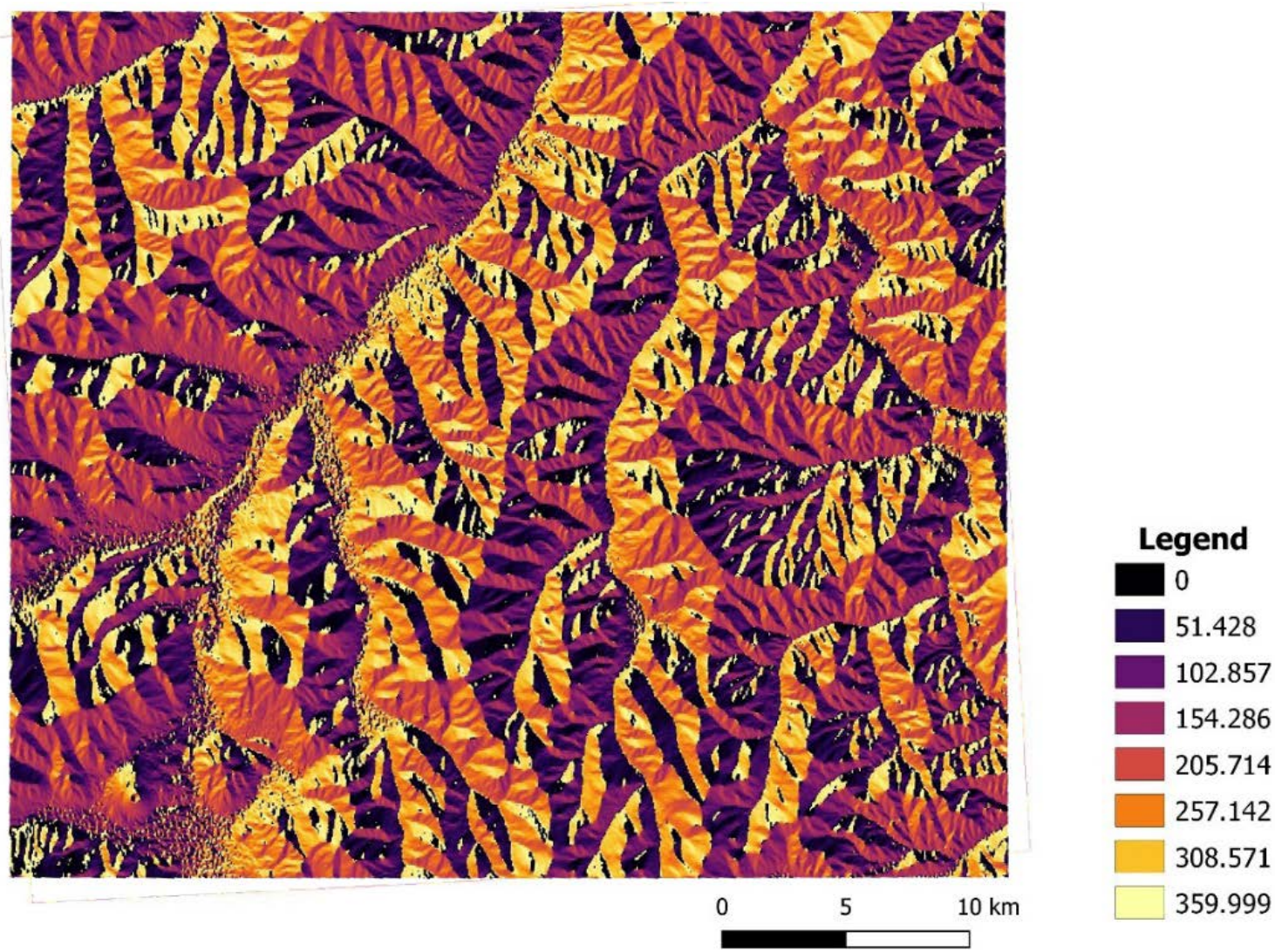

Figure 7. Calculated aspect map from DEM 


\section{Forest type map generation from optical images}

In recent years, object-based classification methods have been successfully applied for a forest mapping. In this method, after an image is segmented into appropriate image objects, it is classified by assigning each object to a class, based on features and criteria set by the user. The values of the parameters define how much influence spectral and spatial characteristics of the image layers will have in defining the shape and size of the image objects. The user modifies the settings, depending on the objective of the study, as well as the image quality, available bands, and image resolution.

As a general rule, reliable image objects should be as large as possible, but small enough to show details of interest [20]. Many authors applied these techniques for the identification of forest classes. Kim et al. (2009) found that segmentation quality, associated with the segmentation scale, directly influences the classification result of forest types using optical imagery. In the method, an improved classification result of forest types, including deciduous broadleaf, evergreen and mixed forests, was achieved [21]. Martin et al. (2014) performed a forest type mapping by combining multisource data using this advanced classification approach. In their method, they established a set of rules using different indices along with other spatial data, and classified the forested areas with an improved accuracy [22]. Nyamjargal et al. (2019) classified mixed forest types in Mongolia using object-based classification and revealed that a thoroughly defined segmentation and a well-constructed rule-base could significantly improve the classification decision-rule [23].

In the current study, to extract the forest class information, initially, we applied a multiresolution segmentation to the selected RS data.
The segmentation parameters to be selected by the user are interrelated to each other. It is impossible to directly find a set of proper segmentation parameters at one time. Users have to repeatedly select a set of segmentation parameters and test them through a trial-anderror process, until a reasonable segmentation result is achieved or the user does not want to continue the trial and error anymore. In our study, shape, color, smoothness and compactness were selected by increasing and decreasing each of the parameters to find the best value that would control the appropriate segmentation. After the trial, the parameters, such as the scale, shape and compactness were set as 80, 0.2 and 0.7, respectively.

After the segmentation, the image objects have been classified into selected forest classes, using threshold values of a normalized difference vegetation index (NDVI). To achieve a reliable classification result, the entire image had to be divided into "vegetation" and "non-vegetation" classes. Then, the "vegetation" class has been sub-divided into "grass" and "forest" classes. After that "forest" class was classified into "evergreen conifers" and "deciduous conifers". The final result of the object-based classification is shown in Figure 8.

In general, a high precision and detailed forest type map can be obtained from remotely sensed images, when accurate ground truth information is available. However, in the present study, it was found that the study area lacked an updated forest type map and most of the existing thematic information was not appropriate for an accurate forest analysis. Therefore, we used an old small scale forest map along with a $1: 100,000$ scale topographic map of 1986 as ground truth information. The selected ground truth data was sufficient to differentiate the evergreen and deciduous conifer types. 


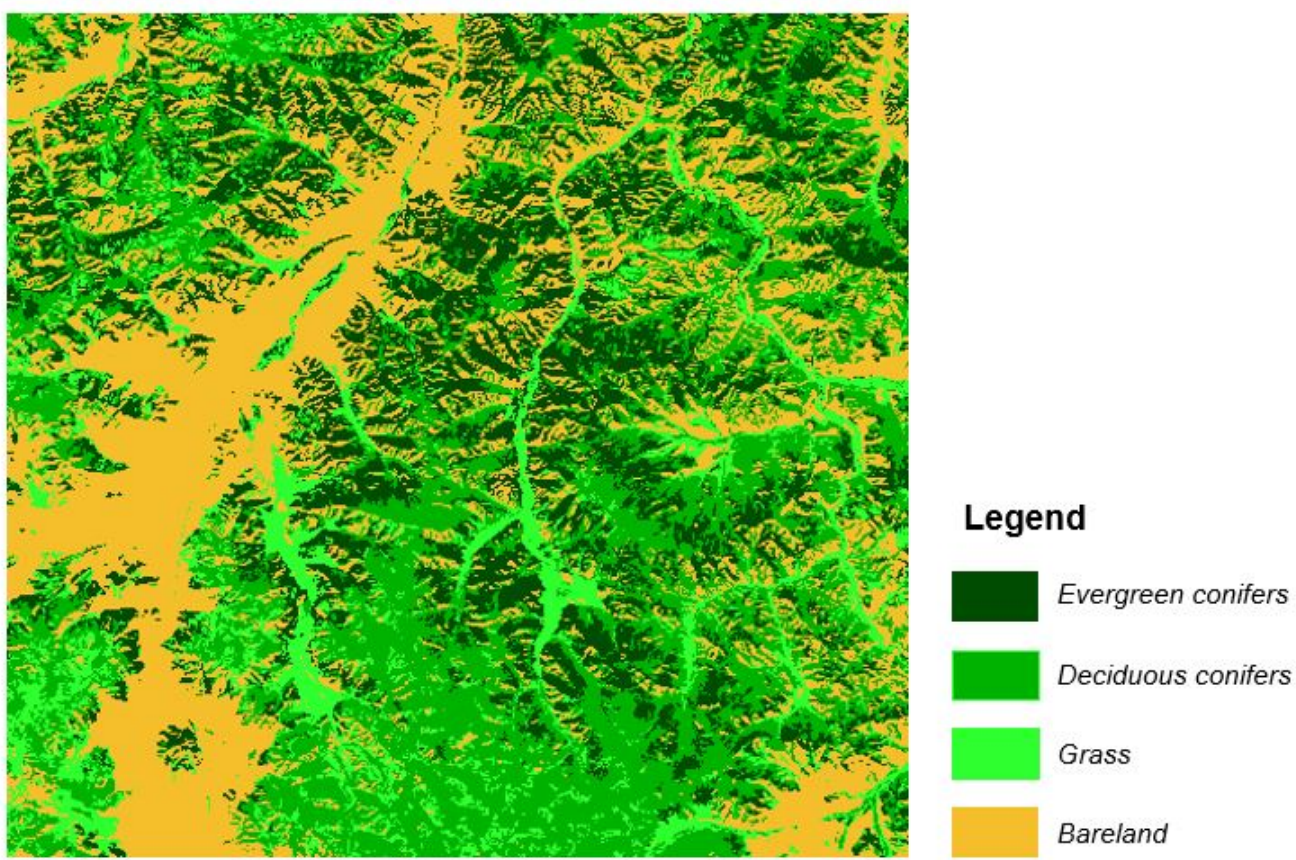

Figure 8. Final result of the object-based classification

Accuracy assessments have been performed based on the sample pixels defined by user experience and error matrices have been created for the classification results (Table 2). As seen from the table, the overall accuracy was 82.29 per cent, while kappa coefficient indicated 0.7561 . The producer's and user's accuracy assessment results of "evergreen conifers" class are higher than those of "deciduous conifers" class which ranged between 82.5 and 91.6 per cent. In terms of "grassland" class, it demonstrates the lowest result compared to other classes. As this study is aimed to examine forest types, we considered that lower accuracy of grassland could be acceptable for further analysis.

Table 2. Accuracy assessment for the object-based classification.

\begin{tabular}{|c|c|c|c|c|c|}
\hline & Evergreen & Deciduous & Grass & Bareland & Total \\
\hline \multicolumn{6}{|c|}{ Ground truth pixels } \\
\hline Evergreen & 7852 & 1666 & 0 & 0 & 9518 \\
\hline Deciduous & 720 & 17823 & 4022 & 0 & 15384 \\
\hline Grass & 0 & 3155 & 11816 & 413 & 14875 \\
\hline Bareland & 0 & 0 & 1065 & 13810 & 22565 \\
\hline Total & 8572 & 22644 & 16903 & 14223 & \\
\hline \multicolumn{6}{|l|}{ Accuracy } \\
\hline Producer (\%) & 91.6 & 78.7 & 69.9 & 97.1 & \\
\hline User $(\%)$ & 82.5 & 79.0 & 76.8 & 92.8 & \\
\hline \multicolumn{6}{|c|}{ Overall accuracy (\%): 82.29} \\
\hline \multicolumn{6}{|c|}{ Kappa coefficient: 0.7561} \\
\hline
\end{tabular}

\section{Overlay (geographical) analysis of forest types}

The concept of this analysis was to combine data on terrain slope and aspect with data on forest type. To manipulate and analyze the data, open-source tools and software have been used (QGIS (Development Team, 2019) and GDAL (GDAL/OGR contributors, 2019)). The spatial intersection of slope and aspect maps and forest type map was computed using the GDAL raster calculator. As a result, aspect and slope values were determined for each pixel of the raster imagery. 


\section{RESULTS AND DISCUSSION}

The results of intersection of the slope map and forest type map is shown in Figure 9. We divided the forest areas into 7 classes with a $10^{\circ}$ interval. As seen from the graph, the first and second slope classes $\left(<20^{\circ}\right)$ supported a smaller percentage of the forested area compared to the other slope classes. Also, it is seen that the evergreen conifers are distributed in larger areas than the deciduous conifers. Especially, the variations in slope distribution between forest types are found on slopes between 30 and 40 degrees. Meanwhile, it is seen that the deciduous conifers occupy larger areas on steeper slopes.

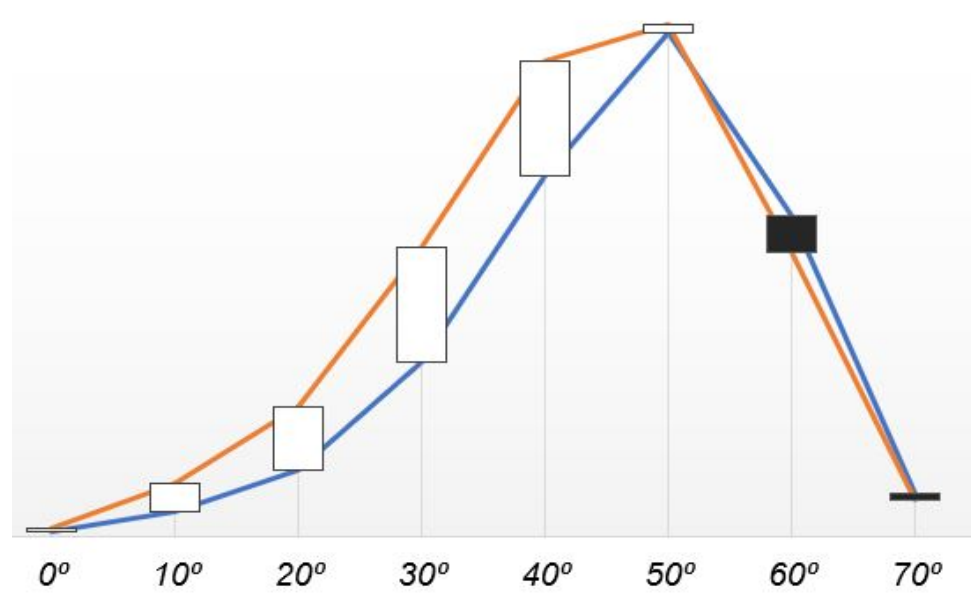

Figure 9. The result of slope map and forest type map analysis

The results of intersection of the aspect map and forest type map is shown in Figure 10. As seen from Figure 10, about one half of the forested area faces towards the north-west, north and north-east directions. On the other hand, less than 27 per cent of the forested area are on the south-facing slopes because of soil moisture. Both of the deciduous and evergreen conifers exhibit the same performance toward the east direction. Moreover, the deciduous conifers have more distribution (18 per cent) in the south and south east directions compared to the evergreen conifers (10 per cent).

On the other hand, evergreen conifers occupy 44 per cent of the total area facing north-west, west and south-west, while deciduous conifers comprises 36 per cent of the total area. It is seen that the evergreen conifers are mainly distributed on slopes between 30 and 50 degrees facing south-west, west and northwest, whereas deciduous conifers are predominantly distributed on steeper slopes facing south east and south. Larix sibiri is a frost-hardy and native deciduous coniferous tree of Mongolia. It grows faster than many other coniferious trees and requires full sunlight [24]. Therefore, we consider that deciduous conifers can have more distribution than evergreen conifers in the south and south-east facing directions. 
Deciduous conifers

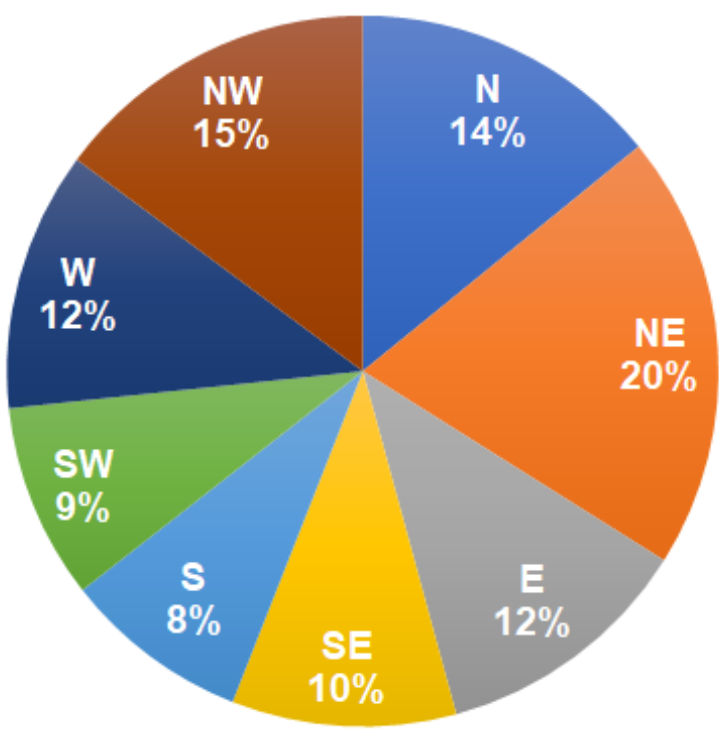

Evergreen conifers

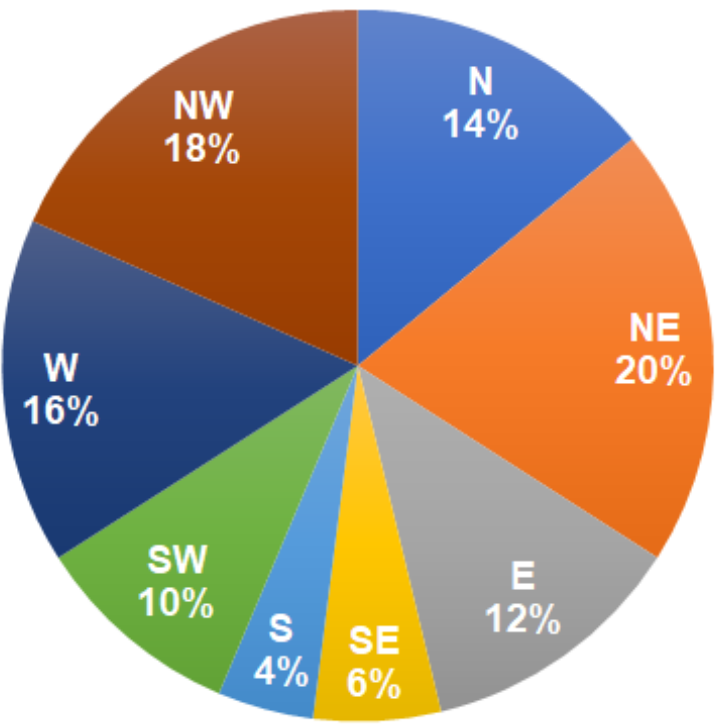

Figure 10. The results of aspect map and forest type analysis

\section{CONCLUSIONS}

The aim of the research was to generate a high resolution DEM and conduct geographical analysis using the forest type, slope and aspect information. As data sources, Sentinel-1 interferometric SAR images and Sentinel-2 multitemporal optical images of Khutag-Undur soum in Bulgan aimag were used. Initially, DEM creation from SAR data was conducted and the output had a pixel resolution of $12 \mathrm{~m}$. Then, the slope and aspect values were calculated from the generated DEM. For

\section{REFERENCES}

1. Eftekhari, A., Ghannadi, A., Motagh, M. and Seresht, M., (2013). "3D object coordinates extraction by radargrammetry and multistep image matching”, ISPRS - International Archives of the Photogrammetry, Remote Sensing and Spatial Information Sciences. XL-1/W3. pp. 147-151. 10.5194/isprsarchives-XL-1-W3-1472013.

2. Makineci, H. B. and Karabörk, H., (2016). "Evaluation Digital Elevation Model Generated by Synthetic Aperture Radar Data”, ISPRS - International Archives of the Photogrammetry, Remote generation of the forest map, object-based classification method, followed by a multiresolution segmentation were applied. Then, geographical analysis was performed using DEM-based slope and aspect maps as well as the optical image-based forest type map. Overall, the study indicated that the combined use of SAR and multispectral images could be successfully used for different geographical analysis, specifically topography-based thematic studies.
Sensing and Spatial Information Sciences, XLI-B1, 57-62. doi:10.5194/isprs-archives-xli-b1-572016.

3. Lazecký, M., Hlaváčová, I., Martinovič, J. and Ruiz-Armenteros, A. M., (2018). "Accuracy of Sentinel-1 Interferometry Monitoring System based on Topography-free Phase Images”, Procedia Computer Science, 138, pp. 310-317. doi:10.1016/j.procs.2018.10.044.

4. Amarsaikhan, D., Sato, M. and Ganzorig, M., (2006). "The thematic information extraction from POLINSAR data for 
urban planning and management”, Invited full paper published in CD-ROM Proceedings of the ISPRS Mid-term Symposium 2006, ITC, The Netherlnads, pp.wg02_1-6.

5. Amarsaikhan, D., (2005). "The thematic information extraction from the Pi-SAR interferometric data”, Scientific papers of Informatics Institute of MAS, pp. 43-48.

6. European Space Agency, (2007). InSAR Principles: Guidelines for SAR Interferometry Processing and Interpretation.

7. Ghannadi, M. A., Saadatseresht, M. and Motagh, M., (2015). "Sentinel-1 Image Matching Using Strong Scatters”. ISPRS - International Archives of the Photogrammetry, Remote Sensing and Spatial Information Sciences, XL-1-W5, 233-235. doi:10.5194/isprsarchives-xl-1w5-233-2015.

8. Yague-Martinez, N., Prats-Iraola, P., Kraus, T., Wollstadt, S. and Scheiber, R., (2016). "Experimental validation with TerraSAR-X/TanDEM-X of advanced interferometric modes for accurate retrieval of azimuthal displacements," 2016 IEEE International Geoscience and Remote Sensing Symposium (IGARSS), Beijing, 2016, pp. 1444-1447, doi: 10.1109/IGARSS.2016.7729369.

9. Nowakowski, T., (2015). "Arianespace successfully launches Europe's Sentinel2A Earth observation satellite". Spaceflight Insider.

10. Sanjmyatav, Z., (2007). Mongolian Geography, Ulaanbaatar, Mongolia.

11. Ministry of Environment and Tourism, (2016). Mongolian Multipurpose national Forest Inventory 2014-2016, 1st Edition. Ulaanbaatar, Mongolia.

12. European Space Agency, (2016). Sentinel-1 Product definition.

13. European Space Agency, (2015). Sentinel-2 User Handbook.
14. Array Systems Computing Inc., (2014). TOPS Interferometry Tutorial.

15. Skywatch Space Application Inc., (2020). TOPS Interferometry Tutorial.

16. Goldstein, R. and Werner, C., (1998). "Radar interferogram filtering for geophysical applications”, Geophysical Research Letters, 25, pp. 4035-4038.

17. Skywatch Space Application Inc., (2020). Interferometry Tutorial with Radarsat-2.

18. Burrough, P. A. and McDonell, R. A., (1998). "Principles of Geographical Information Systems”, Oxford University Press, New York, p. 190.

19. Horn, B., (1981). "Hill shading and the reflectance map", Proceedings of the IEEE. 69. $\quad$ pp. 14 - 47. 10.1109/PROC.1981.11918.

20. Gronemeyer, P., (2012). "Object-based classification”, The Landscape Tool Box, available

at:http://wiki.landscapetoolbox.org/doku. php/remote_sensing_methods:object based_classification.

21. Kim, M., Madden, M. and Warner, T. A., (2009). "Forest type mapping using object-specific texture measures from MS IKONOS imagery: segmentation quality and image classification issues". Photogrammetric Engineering and Remote Sensing, Vol 75, No 7, pp. 819829.

22. Martin, M. and Lucie, Z., (2014). "Forest mapping through object-based image analysis of multispectral and LiDAR aerial data”. European Journal of Remote Sensing, 47:1, pp. 117-131.

23. Nyamjargal, E., Amarsaikhan, D., Munkh-Erdene, A., Battsengel, V. and Bolorchuluun, Ch., (2019). "Objectbased Classification of Mixed Forest Types in Mongolia”. Geocarto International, 35:14, pp. 1615-1626.

24. Farjon, A. (2013). "Larix sibirica". The IUCN Red List of Threatened Species. IUCN. 